\title{
A Survey of Nigerian Family Physicians' Views on the Fundamental Assumptions of Andragogy
}

\author{
Musa Dankyau \\ Department of Family Medicine, Bingham University Teaching Hospital, Jos, Nigeria \\ Email address: \\ dankyau@gmail.com
}

To cite this article:

Musa Dankyau. A Survey of Nigerian Family Physicians' Views on the Fundamental Assumptions of Andragogy. Journal of Family Medicine and Health Care. Vol. 2, No. 3, 2016, pp. 13-16. doi: 10.11648/j.jfmhc.20160203.11

Received: August 28, 2016; Accepted: September 8, 2016; Published: September 30, 2016

\begin{abstract}
Adult learning (andragogy) theory is fundamental to all aspects of health professional education. Physicians have varying beliefs and perceptions of these fundamental assumptions. This study was designed to ascertain the views of Nigerian family physicians regarding the fundamental assumptions of andragogy. A cross sectional survey of all family physicians, specialists and those in training, in Jos, North central Nigeria was carried out using a brief, self-administered questionnaire. There was a $76 \%$ response rate. Respondents were mostly male $(76.8 \%)$ with a mean age of $40.6 \pm 6.99$ years. They had a mean number of years in practice $12.55 \pm 6.37$, median 11 years (range 2-31). Most (64.3\%) were residents and majority (71.1\%) were involved in medical teaching. Majority (89.3\%) agreed with the fundamental assumption of andragogy that "adults have accumulated a great deal of experience, which is a rich resource for learning." The least agreement (49.1\%) was for the fundamental assumption that adults are problem-centered. Similarly, the highest (25\%) overall disagreement was the assumption that adults are more interested in immediate, problem-centered approaches than in subject-centered ones. Multivariate analysis indicated that residents were almost five times more likely than Consultants to agree with the assumption that adults are problem-centered $(\mathrm{OR} 4.9,95 \% \mathrm{CI} 1.02-23.45, \mathrm{P}=0.047)$. There were no significant predictors of agreement with the other fundamental assumptions on multivariate analysis. Family physicians, consultants more than residents, are more likely to disagree with the assumption that adults are problem-centered learners.
\end{abstract}

Keywords: Family Physicians, Andragogy, Adult Learning, Medical Education; Problem-Centered learning

\section{Introduction}

Andragogy is the art and science of adult learning, and the term adult learning was introduced in the 1970s. The core principles of andragogy include: Learners need to know; Self-concept of the learner; prior experience of the learner; readiness to learn; orientation to learning; and motivation to learn. [1] Components of these principles have been applied to medical education in Sub-Saharan Africa with mixed results. [2] A recent review of the application of andragogy principles revealed moderate self-directed learning achieved among students, and a generally positive perception by the Faculty of a medical school in Uyo, South South Nigeria. [3] The principles have also been successfully incorporated into the curriculum of Family Physicians training in remote and rural medicine in Canada. [4] A recent review of the application of andragogy to residency training in Radiology in West Africa indicated the vital need to understand the basic adult learning principles to aid the concept of guided training, since the adult residency trainee shoulders the bulk of the training responsibilities of acquisition of knowledge. [5] It has also been shown that adults learn better from teachers who embrace andragogy. [6]

The aim of this study was to determine the views of Family Physicians attending SOFPON Jos zone quarterly CME regarding the core principles of andragogy. This would enable modifications of teaching methods in residency programs to more appropriately incorporate the core principles of adult learning.

\section{Background}

The Society of Family Physicians of Nigeria (SOFPON), is the umbrella academic body for specialist Family Physicians in Nigeria. The society aims in part to promote Continuing Medical Education and Research among Family 
Physicians. In furtherance of these aims, SOFPON organises quarterly CME programmes. The Jos zone of SOFPON has about 75 members on her database.

\section{Methodology}

A cross sectional survey of all consenting Family Physicians present at the SOFPON Jos zone quarterly CME programme was carried out in May 2016. Informed consent was obtained and a simple self-administered questionnaire was presented to all consenting participants. The fundamental assumptions of andragogy were rephrased as five statements:

Doctors are independent and self-directing

Doctors have accumulated a great deal of experience, which is a rich resource for learning

Doctors value learning that integrates with the demands of their everyday life

Doctors are more interested in immediate, problem-centred approaches than in subject-centred ones

Doctors are more motivated to learn by internal drives than by external ones

Respondents were requested to indicate their views on each fundamental statement using a 5-point Likert scale: Strongly disagree; Disagree; Neutral; Agree; Strongly agree.

Data was collated and analysed in Statistical Package for Social Sciences (SPSS) version 21. (IBM, USA). Data was analysed using rates, chi square for categorical variables and multinomial logistic regression to test for multivariate relationships.

\section{Results}

Out of the 75 Family Physicians on the SOFPON Jos zone database, 57 responded to the survey request giving a $76 \%$ response rate.

The respondents had a mean age of $40.6 \pm 6.99$ years. They were mostly male $(76.8 \%)$, with a mean number of years in practice $12.55 \pm 6.37$, median 11 years (range 2-31), most $(64.3 \%)$ were residents and majority $(71.1 \%)$ were involved in medical teaching. Other details of their characteristics are in table 1.
Table 1. Demographic characteristics of respondents.

\begin{tabular}{|c|c|c|c|}
\hline Characteristics & & Frequency & Percentage (\%) \\
\hline \multirow{6}{*}{ Age group } & $<30$ & 4 & 7.4 \\
\hline & $30-39$ & 19 & 35.2 \\
\hline & $40-49$ & 25 & 46.3 \\
\hline & $50-59$ & 5 & 9.3 \\
\hline & $\geq 60$ & 1 & 1.8 \\
\hline & Total & 54 & 100 \\
\hline \multirow{3}{*}{ Gender } & Male & 43 & 76.8 \\
\hline & Female & 13 & 23.2 \\
\hline & Total & 56 & 100 \\
\hline \multirow{5}{*}{ Years of practice } & $<10$ & 20 & 35.7 \\
\hline & $10-19$ & 26 & 46.4 \\
\hline & $20-29$ & 9 & 16.1 \\
\hline & $\geq 30$ & 1 & 1.8 \\
\hline & Total & 56 & 100 \\
\hline \multirow{5}{*}{$\begin{array}{l}\text { Years of } \\
\text { specialization }\end{array}$} & Resident & 36 & 64.3 \\
\hline & $<10$ & 15 & 26.8 \\
\hline & $10-19$ & 4 & 7.1 \\
\hline & $\geq 20$ & 1 & 1.8 \\
\hline & Total & 56 & 100 \\
\hline \multirow{3}{*}{$\begin{array}{l}\text { Involved in } \\
\text { medical teaching }\end{array}$} & Yes & 38 & 71.7 \\
\hline & No & 15 & 28.3 \\
\hline & Total & 53 & 100 \\
\hline \multirow{3}{*}{$\begin{array}{l}\text { Duration of } \\
\text { medical teaching }\end{array}$} & $<10$ years & 29 & 80.6 \\
\hline & $>10$ years & 7 & 19.4 \\
\hline & Total & 36 & 100 \\
\hline
\end{tabular}

Table 2. Responses of family physicians on andragogy.

\begin{tabular}{|c|c|c|c|c|c|}
\hline Andragogy assumption & SD\# (\%) & D & $\mathbf{N}$ & $\mathbf{A}$ & SA \\
\hline Adults are independent and self-directing & $3(5.3)$ & $10(17.9)$ & $6(10.7)$ & $31(55.4)$ & $6(10.7)$ \\
\hline $\begin{array}{l}\text { Adults have accumulated a great deal of experience, which is a rich } \\
\text { resource for learning }\end{array}$ & $0(0)$ & $4(7.1)$ & $2(3.6)$ & $26(46.4)$ & $24(42.9)$ \\
\hline $\begin{array}{l}\text { Adults value learning that integrates with the demands of their } \\
\text { everyday life }\end{array}$ & $0(0)$ & $3(5.4)$ & $4(7.1)$ & $28(50)$ & $21(37.5)$ \\
\hline $\begin{array}{l}\text { Adults are more interested in immediate, problem-centered } \\
\text { approaches than in subject-centered ones }\end{array}$ & $0(0)$ & $14(25)$ & $11(19.6)$ & $23(41.1)$ & $8(143)$ \\
\hline $\begin{array}{l}\text { Adults are more motivated to learn by internal drives than by } \\
\text { external ones }\end{array}$ & $0(0)$ & $11(19.6)$ & $12(21.4)$ & $27(48.2)$ & $6(10.7)$ \\
\hline
\end{tabular}

SD - Strongly disagree; D - Disagree; N - Neutral; A - Agree; SA - Strongly Agree. 


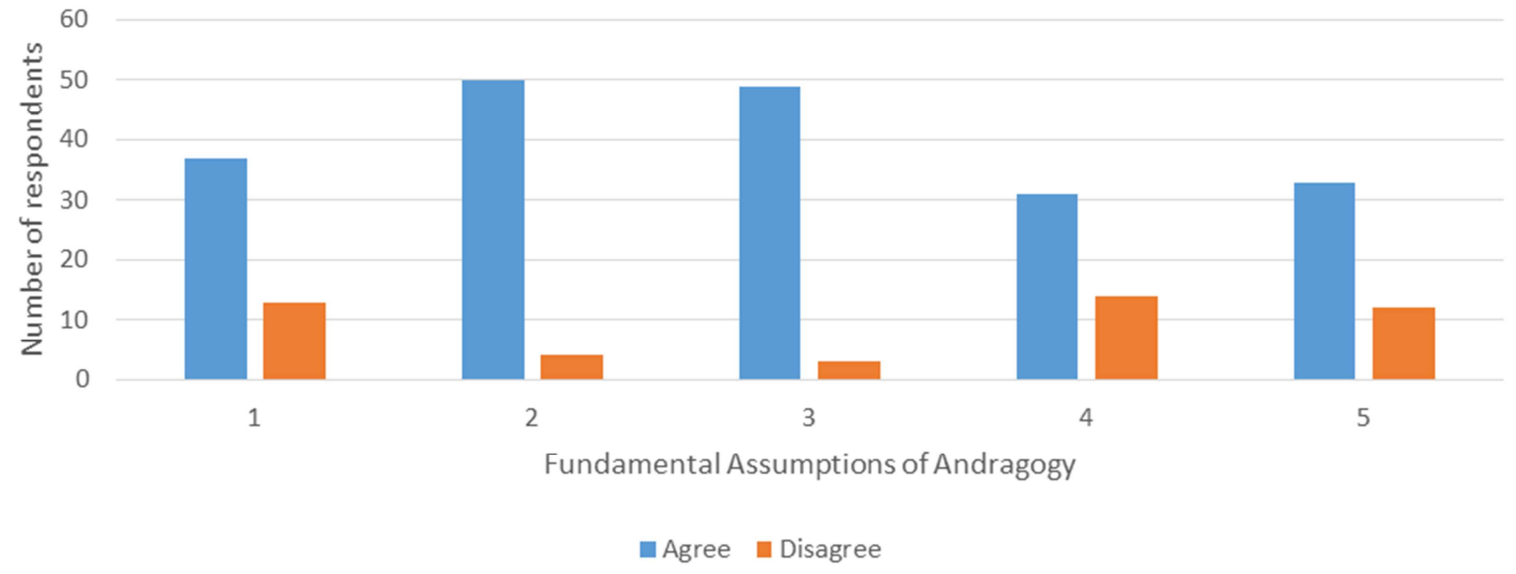

Figure 1. Bar chart showing number of respondents agreeing/disagreeing with andragogy assumptions.

Multinomial logistic regression of did not show any significant predictors of agreement with Assumptions 1, 2, 3 and 5. However, for Assumption 4 which states that "Adults are more interested in immediate, problem-centered approaches than in subject-centered ones" residents were four times more likely than Consultants to agree with this assumption (OR 4.9, 95\%CI 1.02-23.45, P=0.047). Details are in Table 3.

Table 3. Multinomial logistic regression of factors predicting agreement with Fundamental Assumption 4 of andragogy.

\begin{tabular}{lll}
\hline Variables & Adjusted Odds ratio (95\%CI) & P Value \\
\hline Age $(<40$ years) & $0.83(0.12-5.82)$ & 0.85 \\
Gender (Female) & $1.57(0.32-7.80)$ & 0.58 \\
Years of practice ( $<10$ years) & $0.35(0.05-2.75)$ & 0.32 \\
Specialist status (Resident) & $4.90(1.02-23.45)$ & 0.047 \\
\hline
\end{tabular}

\section{Discussion}

This cross sectional study aimed at ascertaining the perspectives of Nigerian Family Physicians regarding the fundamental assumptions of andragogy, had a $76 \%$ response rate. The results showed that the respondents were relatively young, mostly male and majority had been in practice for less than 10 years. This is a reflection of the fact that there were relatively more resident doctors than consultants, and the demographic characteristics mirror similar published studies with large number of residents. [7]

The highest agreement was for fundamental assumption 2 "adults have accumulated a great deal of experience, which is a rich resource for learning" which had an overall $89.3 \%$ of the respondents in agreement. The least agreement (49.1\%) was for fundamental assumption 4. Similarly, the highest $(25 \%)$ overall disagreement was for assumption 4 "adults are more interested in immediate, problem-centered approaches than in subject-centered ones", and assumption 1 (23.2\%) "adults are independent and self-directing". Multivariate analysis also indicated that residents were four times more likely than Consultants to agree with assumption 4 (OR 4.9, 95\%CI 1.02-23.45, $\mathrm{P}=0.047)$. There were no significant predictors of agreement with the other fundamental assumptions on multivariate analysis.
Greysen and colleagues had established the fact that even though medical education had undergone significant changes in the last five decades in Sub Saharan Africa, there was inadequate research and publications particularly in the thematic areas of solution implementation, program outcomes and the development of medical education as a specialized field of inquiry. [2] This has made it difficult to compare these results with evidence based research from this environment. Sadler and colleagues, several decades ago, had reported that Family medicine residents tended towards active and concrete learning styles compared to other specialty areas. [8] Sadler et al made similar conclusions that would then agree with the findings of this study where most family physicians found it easy to agree with the fundamental assumption that "adults have accumulated a great deal of experience, which is a rich resource for learning."

Other investigators had reported that Self-directed learning methods may cause initial fear and confusion for graduate students but ultimately lead to significantly higher satisfaction with learning experience. [9] Payne and colleagues had also reported that longer involvement in education yielded better self-directed learning scores among health professions students. [10] Salih and colleagues had also show that among medical students in Saudi Arabia, gender did not affect self-directed learning scores but higher clinical years yielded higher scores. [11].

This would seem to indicate that family physicians with longer duration of training and practice would tend to agree more with the fundamental assumptions since self-directed learning is an integral implication of andragogy. However, residents were almost five times more likely to agree with the fourth assumption than Consultants. However, Taylor and Hamdick, in their review of adult learning theories, had indicated that although the clinical teaching and learning environment was ideal for using adult learning theories, only reinforcing clear thinking about the principles would actually change both education and clinical outcomes. [12] This is more so in postgraduate medicine where content mastery would appear to be easier in a more focused than a more general specialty like family medicine. In line with these findings, a Continuing Medical Education based on adult 
learning principles led to measurably higher improvement in knowledge intentions patient-centered attitudes and selfesteem of Israeli general practitioners. [13].

\section{Conclusion}

Family physicians in this study tended to agree most with the andragogy assumption that adults have accumulated a great deal of experience, which is a rich resource for learning. They however tended to disagree with the assumption that adults are more interested in immediate, problem-centered approaches than in subject-centered ones". Residents were however more likely to agree with this assumption than consultants. This requires medical teachers and learners especially at postgraduate level to find out whether they and their students do in fact agree with all or some of the fundamental learning theory assumptions underlying their training. Further research into factors responsible for such disagreement are also recommended.

\section{Acknowledgement}

The author wishes to acknowledge the kind assistance of SOFPON Jos zone.

\section{References}

[1] Knowles MS, Holton III EF, Swanson RA. The adult learner: The definitive classic in adult education and human resource development. $8^{\text {th }}$ edition. Routledge. London \& New York. 2014; 18-36.

[2] Greysen SR, Dovlo D, Olapade-Olaopa EO, Jacobs M, Sewankambo N and Mullan F. Medical education in subSaharan Africa: a literature review. Med Educ. 2011; 45 (10): 973-86.

[3] Nottidge TE. Self-directed learning: status of final year students and perceptions of faculty leadership in a Nigerian medical school: a mixed analysis study (Doctoral dissertation, Stellenbosch: Stellenbosch University). 2014.
[4] McCarthy P, Bethune C, Fitzgerald S, Graham W, Asghari S, Heeley T and Godwin M. Curriculum development of 6for6: Longitudinal research skills program for rural and remote family physicians. Can Fam Physician 2016; 62: e89-95.

[5] Arogundade RA. Adult Learning Principles for Effective Teaching in Radiology Programmes: A Review of the Literature. WAJM 2011; 30 (1): 3-10.

[6] Koons, DC. Applying Adult Learning Theory to Improve Medical Education. UCHC Graduate School. Masters Theses 2003-2010. 2004. Paper 51.

[7] Ajuwon GA, Popoola SO. Influence of motivational factors on utilisation of Internet health information resources by resident doctors in Nigeria. The Electronic Library. 2015; 33 (1): 103 19.

[8] Sadler GR, Plovnick M, Snope FC. Learning styles and teaching implications. J Med Educ. 1978; 53: 847-9.

[9] Kirkman S, Coughlin K, Kromrey K. Correlates of satisfaction and success in self-directed learning: relationships with school experience, course format and internet use. International Journal of Self-directed learning. 2007; 4 (1): 39-51.

[10] Payne SS, Rocks J, Schaffner B. Self-direction in learning and academic motivation development in undergraduate health profession students. International Journal of self-directed learning. 2014; 11 (1): 41-51.

[11] Salih M, Sembawa H, Baradwan S, Nuqali A. Self-directed learning readiness among medical students at Umm Al-Qura University, Saudi Arabia: A cross sectional study. Sch Bull. 2016; 2 (1): 20-6.

[12] Taylor DC, Hamdy H. Adult learning theories: Implications for learning and teaching in medical education: AMEE Guide No. 83. Med Teach. 2013; 35 (11): e1561-72.

[13] Margalit AP, Glick SM, Benbassat J, Cohen A, Katz M. Promoting a biopsychosocial orientation in family practice: effect of two teaching programmes on the knowledge and attitudes of practicing primary care physicians. Med Teach. 2005; 27 (7): 613-8. 